\title{
Collectivism and Customer Orientation among Nurses: A Case Study in Iran
}

\author{
Iravan Masoudi Asl ${ }^{1}$, Nasim chavoshi ${ }^{1} \&$ Marzieh Hasanzadeh hosseinabad ${ }^{1}$ \\ ${ }^{1}$ Health Services Management Department, School of Management and Economics, Science and Research \\ Branch, Islamic Azad University, Tehran, Iran \\ Correspondence: Iravan Masoudi Asl, Department of Health Services Management, School of Management and \\ Economics, Science and Research Branch, Islamic Azad University, Tehran, Iran. E-mail: \\ masoudi_1352@yahoo.com
}

Received: December 15, 2014 Accepted: April 8, 2015 Online Published: May 16, 2015

doi:10.5539/ass.v11n13p221

URL: http://dx.doi.org/10.5539/ass.v11n13p221

\begin{abstract}
The mission of organizations is to provide good service for the customers. Weakness in building collectivism morale leads to forgetting group needs and subsequently organizational objectives and customer needs and reduces the patients' referral. On the same ground, the present study was carried out to investigate the relationship between collectivism and customer orientation in nurses' staff which is the most effective hospital staff.

The present analytical study was conducted in 2013 on a group of 200 nurses in a specialty hospital in Tehran. The instruments for gathering data include nurses' demographic information (gender, age, marital status and work experience), collectivism questionnaire (10 questions in three dimensions of beliefs, values and norms), and the checking list of nursing staff's extent of customer orientation (27 questions in 8 aspects). Data analysis was done by SPSS.19 and Spearman's correlation tests, Chi Square, and single-sample T-test.

The results showed that nursing staff had high collectivism morale. Among aspects of customer orientation, the highest and the lowest mean and standard deviation were respectively related to employees' honesty $(2 / 87 \pm 0)$ and employees' appearance $(1 / 71 \pm 0 / 66)$. There was a significant relationship between the two elements of customer orientation and collectivism $(002 / 0=\mathrm{P})$. In addition, apart from the two dimensions of service assurance and employees' appearance, significant relationships were observed between other aspects of customer orientation and collectivism.

Regarding the relationship between collectivism and customer orientation in nursing staff, it can be said that customer orientation in an organization can be promoted by reinforcing collectivism morale in employees. Offering educational programs for promoting collectivism morale and subsequently promoting customer orientation can lead to providing good customer service.
\end{abstract}

Keywords: collectivism, customer orientation, nursing staff, hospital

\section{Introduction}

Mankind always tends to look for his own personal benefits and interests due to loving himself (self-absorption or self-importance) and prefers the method of obtaining gains and repulsing and holding losses back to other policies. Numerous experiences in human communities show that for people caught in the trap of selfishness, there is nothing harder and more painful than observing and obeying the right unless the right is to their personal and group interests and benefits (Triandis, 1995). People in Eastern countries including Iran tend to be more individualistic than collectivist in their everyday busy life; whereas, the approach to scientific activities and sports in Western countries is more cooperative, collaborative, and collective. In Iran, although most successes are partly the product of a collaborative effort and planning, the role of high IQ of Iranian students should not be neglected. If individual intelligence of Iranians is merged and accompanied by a coherent integrated group or team planning and Iranian collective morale and smartness rule and dominate all aspects of social, political and economic life, amazing results will be achieved (Sinha, 2014; Shulruf et al., 2007).

Iran which is already involved in a period of transition from collectivism to individualism is experiencing many challenges during this transition. This is due to advanced traditional collective rules, customs, and traditions and 
due to the fact that individualism is a new issue. Collectivist Iranians are feeling deep frustration encountering new generations who do not show rules and traditional customs respect and they are losing their deep-rooted happiness and prosperity. People do not respect social rules and deep animosity or hatred has formed between ethnics and urban residents. People breach and violate social, civil, human right laws and rules in a variety of ways legally and plainly. These issues all in all are symbols and indications of a transition from collectivism to individualism (Orlikowski, 2006). Another noticeable issue is customer-oriented behavior of employees in various organizations. Kim believes that over the past 40 years, customer orientation has been one of the most important variables in marketing management (Kim et al., 2004). Customer orientation refers to a set of beliefs that directs individuals' behaviors towards customers and clients. In fact, the root of these beliefs is that whatever the customer or client is interested in or whatever is noticeable and favorable for him/her has priority over anything else. In giving priority to the interests and demands of customers, enough attention is paid to organization or institution's interests and goals because considering customers will provide long-term interests of the customers of organization on behalf of customers (Brady \& Cronin, 2001; Hartline et al., 2000). On the other hand, despite the fact that customer orientation is extremely important for most organizations and institutions, this importance is more prominent and outstanding in service organizations. Hoffman and Ingram believe that customer orientation for a service organization is equal to the concept of marketing for a production organization (Hoffman \& Ingram, 1992). On the other hand, customers' perception of the quality of provided services directs their behavior towards service systems' employees and consequently this behavior has significant impacts on employees (Lin, 2008; Majamaa et al., 2008). The most outstanding impact that more recent researches in the field of services organizations' personnel mention is feeling satisfaction and willingness and tendency to show more decent, appropriate, and effective behaviors with customers and clients (Moorman \& Blakely, 1995; Dimitriades, 2007). Regarding the period of transition from collectivism to individualism in Iran and as a result, the impact of this trend on service organizations such as hospitals, employees' tendency to work in line with individual or personal desires, interests, and benefits is rising and unwillingness to work together or team work even in a small group of staff can all lead to the gradual oblivion of group goals and subsequently organizational objectives and lead organizations to collapse in today's competitive environment (Ghorbani et al., 2003; Amin, 2004). Because the mission of organizations is mostly providing good service to the customers, weakness in collectivism morale can bring about forgetting group needs, organizational objectives, and customers' needs after which the organization may gradually face increasing reduction in the number of its clients. Since nurses are more in touch and contact with customers (patients) than other employees of the hospital, understanding the extent of employees' collectivism and determining its relationship with customer orientation is of particular importance in order to provide the necessary training and education for nursing staff, and strengthening the collectivism morale in them. As a result, with the increase in customer-oriented behaviors in employees, the organization can further achieve its mission and philosophical existence which is providing good service to the customers.

\section{Method}

The present research was performed in 2013 at a kidney and urinary tract specialty center. The population of this study was 200 nurses working at hospital among which 132 nurses were selected based on Morgan Chart. Data collection included three parts. The first section contains demographical information of nurses' gender, age, marital status and years of service or work experience. The second part was a questionnaire for assessing collectivism in nursing staff which was previously used in Moorman et al.'s study(Moorman and Blakely, 1995) The questionnaire consisted of 10 questions on the three dimensions of beliefs, values, and norms which was classified based on the five-point Likert scale $(5=$ strongly agree, $4=$ Agree, $3=$ somewhat agree, $2=$ Disagree $1=$ strongly disagree). Except for the first three questions related to beliefs which are reversely scored, scoring the remaining questions is classified as "strongly agree" options with five points and "strongly disagree" options with one point. In addition, 3/5-5 points as highly collectivist and 2/5-3/5 as moderate collectivist, and 1-2/5 points are considered as low collectivist. Its validity was determined by the experts and its reliability was determined by Cranach's alpha to be 0.94 . The third section is a researcher-made checking list to assess the level of customer orientation in nursing staff which consists of 27 questions on employees' knowledge, stable performance, observance of confidentiality, employees' honesty, service assurance, personal or individual attention to customers, employee's appearance and good working atmosphere on a three-point Likert scale ( $3=$ completely, $2=$ partly, $1=$ scarcely). The validity of this instrument was obtained by content analysis method.

Before the study, the hospital officials were informed about the procedure and the questionnaires were taken by nurses. The customer orientation checking list was supplemented by interviews and observations by the researcher. Explanations and descriptions about the study were given to nurses at the time of completing 
questionnaires and sufficient time was given to them. Data analysis is performed at two levels, descriptive statistics (frequency, frequency percentage, mean, and standard deviation) and inferential statistics (Spearman correlation test) using SPSS.19 software.

Because nurses are more in touch and contact with customers (patients) than other employees of the hospital. This research was approved by the hospital's ethics and research committee. Written authorization was obtained from hospital included in the study.

\section{Results}

Among the respondents, 9.4 percent were male and 54 percent were single. The age average of the respondents was 30.5 years, 12 individuals (10\%) with an age average of less than 25 years, 85 individuals $(73 \%)$ with an age average between 25 to 35 years, 14 individuals (12\%) with an age average of 35 to 45 years and 5 individuals (4\%) were over 45 years. The average of work experience of the respondents was 8/24 years, 34 individuals (31\%) with a work experience of less than 5 years, 44 individuals (40/5\%) with an average work experience of 5 to 10 years, 21 individuals (19\%) with an average work experience of between 10 and 15 years, 4 individuals (4\%) with an average work experience of 15 to 20 years and 6 individuals $(5 / 5 \%)$ had a working experience of more than 20 years. Based on Chi-square test, there was a significant relationship between collectivism and the two variables of age and work experience $(\mathrm{P}<0 / 05)$. In addition, based on single-sample $\mathrm{T}$ test, there was a significant relationship between collectivism and the two variables of gender and marital status.

Among the dimensions of collectivism, the highest mean and standard deviation was related to beliefs $(3 / 95 \pm 0 / 99)$ and the lowest mean and standard deviation was related to norms $(3 / 33 \pm 0 / 51)$. The mean and standard deviation of collectivism was obtained to be $3 / 76 \pm 0 / 66$ which indicates that nurses have a sense of collectivism morale (3/67 out of 5 points). Among the aspects of customer orientation, the highest and lowest

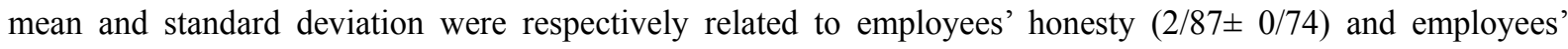
appearance $(1 / 71 \pm 0 / 66)$ (Table 1$)$.

Table 1. Mean and standard deviation of the components of collectivism and customer orientation

\begin{tabular}{lll}
\hline Components & Score & Standard Deviation \\
\hline Beliefs & $39 / 54$ & $2 / 99$ \\
Values & $39 / 98$ & $3 / 10$ \\
Norms & $33 / 34$ & $3 / 21$ \\
Collectivism & $37 / 62$ & $3 / 66$ \\
Employees' Knowledge & $2 / 67$ & $0 / 17$ \\
Stable Performance & $2 / 54$ & $0 / 50$ \\
Observance of Confidentiality & $1 / 99$ & $0 / 29$ \\
Employees' Honesty & $2 / 87$ & $0 / 74$ \\
Service Assurance & $2 / 44$ & $0 / 65$ \\
Personal or Individual Attention to Customers & $2 / 38$ & $0 / 36$ \\
Employees' Appearance & $1 / 71$ & $0 / 66$ \\
Good Working Atmosphere & $2 / 65$ & $0 / 52$ \\
Customer Orientation & $2 / 40$ & $0 / 45$ \\
\hline
\end{tabular}

Table 2. The relationship between collectivism and dimensions of customer orientation

\begin{tabular}{lll}
\hline Components & Correlation Coefficient & Significance Level \\
\hline Customer Orientation & $0 / 803$ & $0 / 002$ \\
Employees' Knowledge & $0 / 643$ & $0 / 033$ \\
Stable Performance & $0 / 878$ & $0 / 000$ \\
Observance of Confidentiality & $0 / 691$ & $0 / 019$ \\
Employees' Honesty & $0 / 603$ & $0 / 049$ \\
Service Assurance & $0 / 161$ & $0 / 636$ \\
Personal or Individual Attention to Customers & $0 / 948$ & $0 / 000$ \\
Employees' Appearance & $-0 / 100$ & $0 / 769$ \\
Good Working Atmosphere & $0 / 724$ & $0 / 012$ \\
\hline
\end{tabular}


As Table 2 shows, there is a relationship between customer orientation and its dimensions with collectivism by Spearman correlation test. There was a significant relationship between the two components of customer orientation and collectivism $(\mathrm{P}=0 / 002)$. Moreover, except from the two dimensions of service assurance and employees' appearance, significant relationships were observed between other aspects of customer orientation and collectivism (Table 2).

\section{Discussion}

In this study, a significant relationship was observed between nurses' collectivism morale and customer orientation. The results of the present study correspond to the results obtained by Zarei Matin et al.'s study (2009) which dealt with designing a cultural and organizational model for customer-oriented organizations and confirmed a significant relationship between customer orientation and the culture of citizen-organizational behavior (Matin et al., 2009), since investigating collectivism morale in organizational culture and the desire to work with others and their relationship with customer orientation leads to strengthening collectivism in employees which consequently reinforces customer-oriented behaviors. In a study by Azadeh (Azam \& Tavakoli, 2007), it was shown that integrity, obeying, and following the group are emphasized in a collectivist society. Everyone's behavior is a reflection of favorable norms in a society. A collectivist person has shared goals with the group; therefore, behaves like other people and accepts social orders as indisputable norms. These conclusions are in line with the results of the present study which confirm the relationship between collectivism and customer orientation. Like the study by Mechida (Mechinda \& Patterson, 2011), that dealt with investigating the effect of the personality of the service provider on the customer-oriented behavior of the nursing staff in five public and private hospitals in Thailand and confirmed the role of personality on customer-oriented behaviors of the nursing staff, the present study approves the relationship between collectivism and customer orientation.

In a study by Lanjananda (Lanjananda \& Patterson, 2009), it was shown that people who tend to be collectivist in personality are more successful in customer-orientation behavior.

Based on the results of the study, there were significant relationships between employees' knowledge, stable performance, observance of confidentiality, employees' honesty, personal or individual attention to customers, and good working atmosphere and nurses' collectivism. The studies by Lung Tan $\mathrm{Lu}$ on the effects on customer orientation in 13 hotels in Taipei (Lu, 2006), Lenard on the bank managers of five Asian and two American countries (Huff \& Kelley, 2005), Yilmaz on factories in Turkey (Yilmaz et al., 2005; Stan et al., 2003; Brown et al., 2002) all show a significant relationship between the collectivism morale and the customer orientation and the dimensions related to customer orientation. The results of the present study show a significant relationship between nurses' demographic variables and collectivism which are in contradiction to the results of the studies by Khanjani and Pak Daman (2011) and Mortazavi and Barzideh (2008). It can be due to differences in sample and instrument.

Regarding the significant positive relationship between collectivism and customer orientation in nursing staff, it can be said that by enhancing and strengthening employees' collective morale, customer orientation can be improved in an organization. Since the hospital is one of the most important organizations in the health care system and deals with the health and life of humans, observing issues of customer orientation and their reinforcement can be of great importance. First, it should be attempted to form teams in hospital organization and then a program should be planned and codified by hospital managers. There should be adequate supervision for the implement of the program. It is recommended that for hiring and employing new staff and individuals, measures should be adopted so that culture is consistent with the organization's strategic beliefs.

\section{Conclusion}

One of the major initiatives is education in socialization. The organization should revise the reward system so that members' cooperation is strengthened. Holding periodic training courses on customer-oriented behavior and reviewing employees' complete readiness to have work skills is another action that can be taken.

\section{Research Limitations}

1) Regarding collectivism and customer orientation, few research studies have been conducted and there were few scholarship resources available.

2) For completing customer orientation checking lists, the researcher had to coordinate with the matron of the hospital in this regard which was difficult due to the busy hospital matron. 


\section{Acknowledgments}

The Authors would like to thank all participants for their kind cooperation with the researchers in collecting the data.

\section{References}

Amin, C. M. (2004). Importing" Beauty Culture" into Iran in the 1920s and 1930s: Mass Marketing Individualism in an Age of Anti-Imperialist Sacrifice. Comparative Studies of South Asia, Africa and the Middle East, 24, 79-95. http://dx.doi.org/10.1215/1089201X-24-1-81

Azam, A. M., \& Tavakoli, A. (2007). Individualism, communalism and religiosity. Journal of the Iranian association of cultural studies and communications, 1, 101-125.

Brady, M. K., \& Cronin, J. J. (2001). Customer orientation effects on customer service perceptions and outcome behaviors. Journal of Service Research, 3, 241-251. http://dx.doi.org/10.1177/109467050133005

Brown, T. J., Mowen, J. C., Donavan, D. T., \& Licata, J. W. (2002). The customer orientation of service workers: Personality trait effects on self-and supervisor performance ratings. Journal of Marketing Research, 39, 110-119. http://dx.doi.org/10.1509/jmkr.39.1.110.18928

Dimitriades, Z. S. (2007). The influence of service climate and job involvement on customer-oriented organizational citizenship behavior in Greek service organizations: a survey. Employee Relations, 29, 469-491. http://dx.doi.org/10.1108/01425450710776290

Ghorbani, N., Bing, M. N., Watson, P., Davison, H. K., \& Lebreton, D. L. (2003). Individualist and collectivist values: Evidence of compatibility in Iran and the United States. Personality and Individual Differences, 35, 431-447. http://dx.doi.org/10.1016/S0191-8869(02)00205-2

Hartline, M. D., Iii, J. G. M., \& Mckee, D. O. (2000). Corridors of influence in the dissemination of customer-oriented strategy to customer contact service employees. Journal of Marketing, 64, 35-50. http://dx.doi.org/10.1509/jmkg.64.2.35.18001

Hoffman, K. D., \& Ingram, T. N. (1992). Service provider job satisfaction and customer. Journal of Services Marketing, 6, 68-78. http://dx.doi.org/10.1108/08876049210035872

Huff, L., \& Kelley, L. (2005). Is collectivism a liability? The impact of culture on organizational trust and customer orientation: a seven-nation study. Journal of business research, 58, 96-102. http://dx.doi.org/10. 1016/S0148-2963(02)00478-2

Kim, J. Y., Moon, J., Han, D., \& Tikoo, S. (2004). Perceptions of justice and employee willingness to engage in customer-oriented behavior. Journal of services marketing, 18, 267-275. http://dx.doi.org/10.1108/0887 6040410542263

Lanjananda, P., \& Patterson, P. G. (2009). Determinants of customer-oriented behavior in a health care context. Journal of Service Management, 20, 5-32. http://dx.doi.org/10.1108/09564230910936832

Lin, W. B. (2008). Factors enhancing the intentions of employees toward customer-oriented behaviors. International Journal of Commerce and management, 18, 267-288. http://dx.doi.org/10.1108/1056921 0810907173

Lu, L. (2006). The Effects of Culture, Customer Focus, and Job Satisfaction on Frontline Employee's Intention of Leaving. The Journal of Global Business Management, 2, 207-216.

Majamaa, W., Kuronen, M., Heywood, C., \& Kostiainen, J. (2008). A consumer-oriented technique for planned residential developments. International Journal of Housing Markets and Analysis, 1, 231-245. http://dx.doi. org/10.1108/17538270810895088

Matin, H. Z., Jandaghi, G., Khanifar, H., \& Heydari, F. (2009). Designing a competent organizational culture model for customer oriented companies. African Journal of Business Management, 3, 281-293.

Mechinda, P., \& Patterson, P. G. (2011). The impact of service climate and service provider personality on employees' customer-oriented behavior in a high-contact setting. Journal of Services Marketing, 25, 101-113. http://dx.doi.org/10.1108/08876041111119822

Moorman, R. H., \& Blakely, G. L. (1995). Individualism-collectivism as an individual difference predictor of organizational citizenship behavior. Journal of organizational behavior, 16, 127-142. http://dx.doi.org/ 10.1002/job.4030160204

Mortazavi, S., \& Barzideh, H. (2008). The relation between cultural collectivism and dependent self-concept 
with critical thinking in shahid beheshti students. Journal of psychological science, 6, 338-353.

Orlikowski, W. J. (2006). Material knowing: the scaffolding of human knowledge ability. European Journal of Information Systems, 15, 460. http://dx.doi.org/10.1057/palgrave.ejis.3000639

Pak, D. S., \& Khanjani, M. (2011). The role of understood growing in children in relation with affiliation styles and collectivism in students of universities. Quarterly of psychology and social researches, 1, 81-102.

Shulruf, B., Hattie, J., \& Dixon, R. (2007). Development of a new measurement tool for individualism and collectivism. Journal of Psycho-educational Assessment. http://dx.doi.org/10.1177/0734282906298992

Sinha, J. (2014). Collectivism and Individualism. Psycho-Social Analysis of the Indian Mindset, 27-51. http://dx.doi.org/10.1007/978-81-322-1804-3_2

Stan, S., Evans, K. R., Cernusca, D., \& Sengupta, S. (2003). Retailing evolution and revolution in a privatizing economy: small business managers' values and retail strategies in Romania. Journal of Euro-marketing, 12, 55-77. http://dx.doi.org/10.1300/J037v12n03_05

Triandis, H. C. (1995). Individualism \& collectivism. Westview Press.

Yilmaz, C., Alpkan, L., \& Ergun, E. (2005). Cultural determinants of customer-and learning-oriented value systems and their joint effects on firm performance. Journal of Business Research, 58, 1340-1352. http://dx.doi.org/10.1016/j.jbusres.2004.06.002

\section{Copyrights}

Copyright for this article is retained by the author(s), with first publication rights granted to the journal.

This is an open-access article distributed under the terms and conditions of the Creative Commons Attribution license (http://creativecommons.org/licenses/by/3.0/). 